\title{
Exploring Energy Efficiency and Service Quality of Airlines with Cruise Speed Control
}

\begin{abstract}
S. Gholami ${ }^{1, *}$, M. Jalalian ${ }^{2}$, R. Ramezanian ${ }^{3}$
In the past decade, fuel consumption and $\mathrm{CO}_{2}$ emission have increased in the airline industry. Large $\mathrm{CO}_{2}$ footprint has a damaging effect on the environment. Global concerns over this issue have made the airline industry to be greener. Most efforts of the green airline industry are improving the fuel consumption to reduce the $\mathrm{CO}_{2}$ emission and its environmental damage. Here, we use cruise speed control to control the fuel consumption and $\mathrm{CO}_{2}$ emission. Each aircraft has a different speed level needing a different fuel consumption. Service quality is studied besides the energy consumption. We investigate two objectives including total energy consumption (TEC) and passenger service level (PSL). TEC and PSL are conflicting in nature. We develop a mixed-integer nonlinear programming model to integrate schedule design, aircraft assignment and maintenance routing problems. We make use of the augmented E-constraint method to solve the problem. To evaluate the model, a real data based on the Emirates airline flights is used. The results are compared using four different scenarios.
\end{abstract}

Keywords: Green airline, $\mathrm{CO}_{2}$ emission, Cruise speed control, Schedule design, Aircraft assignment, Maintenance routing.

Manuscript was received on 04/05/2017 revised on 10/10/2017 and accepted for publication on 08/11/2017

\section{Introduction}

Airline industry has a fundamental role in developments of countries. This industry provides fast transit for goods, fast travels for passengers and make travels easy [1]. Airline industry is a tough aviation market with a tight competition, low profit margins and high costs [5]. Among all airline sources, the highest cost with a share of more than $30 \%$ is assigned with the fuel consumption [11]. The small improvement in this cost can lead to large saving that. The latest report of intergovernmental panel on climate change (IPCC) [2] expressed the transport sector consumed $27 \%$ of the energy and released 6.7 GT carbon dioxide $\left(\mathrm{CO}_{2}\right)$ in 2010 . They also predicted that if the transport industry does not consider a steady policy, then the industry will become the biggest source of $\mathrm{CO}_{2}$ emission. The airline industry as a part of air transport industry has a rapid growth rate in energy consumption which is more than $6 \%$ over the past 10 years [10]. Fuel consumption emits $\mathrm{CO}_{2}$. With this amount of fuel consumption, the airline industry emits about $2 \%$ of the $\mathrm{CO}_{2}$ in the world [15]. This emission pollutes the atmosphere and has a damaging effect on the

\footnotetext{
* Corresponding Author.

${ }^{1}$ Department of Industrial Engineering, K.N. Toosi University of Technology, Tehran, Iran, Email: s_gholami@kntu.ac.ir.

${ }^{2}$ Department of Industrial Engineering, K.N. Toosi University of Technology, Tehran, Iran, Email: Mahdi.Jalalian@email.kntu.ac.ir.

${ }^{3}$ Department of Industrial Engineering, K.N. Toosi University of Technology, Tehran, Iran, Email: Ramezanian@kntu.ac.ir.
} 
environment [39]. Also, there is a limit on $\mathrm{CO}_{2}$ emission in some countries [10]. Therefore, the airline industry tries to be eco-friendly and greener to reduce the damaging environmental effect. Green consideration has an economic benefit besides the positive environmental effects. Green efforts reduce the fuel consumption and $\mathrm{CO}_{2}$ emission in the airline industry. In this way, the fuel cost is reduced. Therefore, managers can price flight ticket at a lower rate. High prices have negative effects on customer loyalty [25], but low prices can attract more passengers and increases the market share. Green efforts can increase revenues by reducing costs and ticket prices. Also, positive publicity of green airlines encourages passengers to pay more for green flights as they pay more for better services [19]. Service quality is another important element to attract passengers. Improving the service level increases passengers' satisfaction and loyalty.

Many researchers in operational research took advantage of optimization problems to reduce costs [9]. Results of operational research in the airline problems including schedule design, aircraft assignment and maintenance routing have proven to be effective for the industry [4]. We propose a new bi-objective mixed-integer nonlinear programming (MINLP) model to integrate schedule design, aircraft assignment and maintenance routing problems. We focus on total energy consumption and passenger service level as two conflicting objectives. We consider cruise speed control to overcome the conflict. Not having an effective model may lead to catastrophic damages. For example, an accident occurred for the Brazilian football players while traveling from Brazil to Colombia killing 72 passengers. The accident was due to inappropriate aircraft assignment to the flight. Aircraft fuel tank capacity was not enough for the flight. Therefore, the fuel finished before aircraft reached the destination (https://www.theguardian.com).

The main contributions of our work are as follows:

1. Proposing a new modeling approach to integrate the schedule design, aircraft assignment and maintenance routing problem.

2. Developing the multiday planning for the proposed model.

3. Developing the new concept for passenger service level.

4. Analyzing the conflict between the total energy consumption and passenger service level.

5. Evaluating the efficiency of the model based on a real data from the Emirates flights.

The rest of the paper is organized as follows. Section 2 reviews the relevant literature. Section 3 presents a mathematical model and a solution method. Section 4 presents computational results and analysis. Section 5 gives our concluding remarks and some suggestions for future research.

\section{Literature Review}

There are several studies for schedule design, aircraft assignment, maintenance routing and crew scheduling. Studies on these issues considering cruise speed control (CSC) have been studied less. In recent years, CSC has attracted researchers in operational research.

Turgut et al. [38] studied the criteria affecting fuel consumption in the air transport. These criteria include cruise altitude, cruise flight time, aircraft speed and its mass. They proposed empirical model based on collected data from the Turkish airlines. The data were analyzed to find relations between the fuel consumption and the above criteria. The results showed that the relations had normal distributions. Franco and Rivas [14] examined the effect of average horizontal wind and the aircrafts weight on minimum aircraft fuel consumption. They considered the altitude and arrival time as constant values and then calculated the optimal solution. The influence of altitude and aircraft weight was also analyzed on the optimal results. Fukui and Miyoshi [15] studied the effect 
of fuel tax on the consumption. They offered a regression analysis to predict the impact of the aviation tax on fuel consumption. According to their results, an increase in the aviation fuel tax reduces the fuel consumption just in the short run. They noted that the small carriers were impressed more by energy prices as compared to the large ones. Their results showed that tax is merely a supplementary tool to influence energy consumption and is not enough by itself. Lim and Hong [28] surveyed the fuel hedging. Fuel hedging is known as a tool to reduce the risk against the fuel cost changes. Besides the little profit of fuel hedging, it has a poor negative impact on costs. Hedging policy, except for normal economic times, is not efficient.

Passengers play important roles in the airline industry. Some studies have examined different criteria affecting passenger satisfaction. Jiang and Zhang [25] studied the impact of service quality on customer satisfaction and loyalty. They made an empirical study based on the collected data from the airports in China. They formed a three-sections questionnaire and used the Probit model to assess different factors affecting the customer loyalty. They divided passengers into two groups based on leisure and business travels. The effects of the factors are different for these groups. Ticket price has a positive effect on passenger satisfaction and loyalty. Kurtulmuşoğlu et al. [26] studied behaviours of passengers to identify the most important priorities for their expectations. They said that airlines should listen to passengers' voice and attend to their expectation, but it is difficult or even impossible to answer all their expectations. They used the Stochastic Multi-Criteria Acceptability Analysis-2 (SMAA-2) method to study the passengers' priorities. Based on the results, ticket price was identified as the most important factor for passengers. Hagmann et al. [19] studied a passengers' tendency to green airline. They distributed self-completion questionnaires among passengers waiting in the Dusseldorf airport in Germany. The goal was to collect data about the passengers' imaginations about green airlines or their environment friendliness. They used a non-parametric test to analyze the data. The results showed that there is a difference between airlines based on the green image. Abdullah et al. [1] introduced three key benchmarking criteria to reach the green concept. They include daily activities, corporate environment management practices and strategic planning. Their research introduced green airline as a new concept. They introduced flight planning optimization to reduce fuel burn. Cui et al. [10] discussed fuel management. They focused on the criteria measuring the airline energy efficiency. They proposed a new Virtual Frontier Dynamic Slacks Based Measure model. An empirical study was conducted based on the collected data from 21 airlines during the period 2008 to 2012. They described three kinds of data containing input, output and dynamic factors. They used the second-stage regression to analyze the data. Input data included the number of employees and aviation kerosene. Output data included revenue tonne kilometers, revenue passenger kilometers and total business income. Dynamic factor included capital stocks.

All the above studies examined energy consumption and service quality from the managerial point of view. There are a few studies surveying cruise speed control. Aktürk et al. [3] presented a first study for aircraft rescheduling applying the CSC. They used CSC to recover the schedule from disruptions. To show the effectiveness of recover framework, they tested three approaches including push-back recovery, CSC and aircraft swap. They proposed a MINLP model to study the trade-off between flight delays as disruption and cost of recovery. They used conic mixed integer programming and strengthened conic reformulation to handle the problem. Duran et al. [12] developed a MINLP model considering CSC. They also used an idle time insertion to create a robust airline schedule. They used CSC and idle time insertion together to analyze the passenger connection. The presented model tries to achieve the minimum costs for passenger connection through chance constraints. For the first time, they transferred the nonlinear constraint to second order conic inequalities. Gürkan et al. [18] considered a daily planning horizon with CSC. They developed a MINLP model for airline scheduling and aircraft assignment. A second order conic 
reformulation was used to mitigate the computational difficulty. They surveyed a trade-off between the number of aircrafts needed to fulfill passenger demands and the overall fundamental costs. They proposed two heuristic methods to solve large instances. Şafak et al. [33] studied a robust schedule with CSC. They used a mix-integer second order conic program approach. They examined the trade-off between energy consumption and passenger connection through chance constraints. They also proposed a heuristic method to solve the problem in a reasonable time.

The literature review shows that the service quality has not been considered by the available models. According to our knowledge, no one has studied both energy consumption and service quality. We consider these two factors to integrate the schedule design, aircraft assignment and maintenance routing problem. In the following section, we discuss our proposed model.

\section{Problem Definition and Mathematical Model}

Our studied problem consists of 3 stages including schedule design, aircraft assignment and maintenance routing problem. Stage 1 designs flights based on demands. Then, the start and finish times of flights are fixed. Stage 2 assigns aircrafts to flights based on the aircraft size and the demands for flights. Stage 3 assigns routes to the aircrafts to cover all the flights. This stage considers maintenance simultaneously with routing. Therefore, stage 3 is involved with routing and maintenance and is called maintenance routing problem. In this problem, the aircrafts cover different flights while ensuring proper maintenance. There are four types of maintenance named as A, B, C and D. Duration time of maintenance and duration time between two successive maintenance increase from type A to type D [36]. The proposed model is designed to solve in a short-term planning horizon. Only maintenance type A occurs during this period. So, the other types of maintenance are not considered in the modeling. We aim to address the integrating schedule design, aircraft assignment and maintenance routing for multiday planning considering the energy consumption and service level. We propose a bi-objective MINLP model to minimize TEC and maximize PSL (minimize the cost). The airline problem including aircraft routing by itself is known to be NP-hard [32]. Obviously, our bi-objective problem with the aim of integrating schedule design, aircraft assignment and maintenance routing with cruise speed control is not less complicated as compared to the aircraft routing problem. We proposed a new approach in modeling the proposed problem.

\subsection{Proposed MINLP Model}

Our assumptions are as follows:

- Departure and arrival times of each flight will occur in one day.

- Speed of the aircraft is constant during the cruise flight time.

- There is a time limit for starting the maintenance.

The indices, parameters and decision variables are defined as follows:

$\begin{array}{cl}\text { Indices } & \\ i, j & \text { Index for flight } \\ t & \text { Index for aircraft } \\ d & \text { Index for day }\end{array}$


$l \quad$ Index for speed level.

\section{Parameters}

\begin{tabular}{|c|c|}
\hline$F$ & Set of flights \\
\hline$T$ & Set of aircrafts \\
\hline$D$ & Set of planning days ( $d_{l t}$ represents the last day in planning period) \\
\hline$L$ & Set of speed levels \\
\hline$u_{i}$ & $\begin{array}{l}\text { Set of flights following flight } i \text { in term of origin and destination. The flight origin in } \\
\text { set } u_{i} \text { should be the same as the destination of flight } i\end{array}$ \\
\hline$F M_{t}$ & $\begin{array}{l}\text { Maintenance for aircraft } t \text { that should be performed at the destination of flights } \\
\text { included in this set }\end{array}$ \\
\hline$N(F)$ & Number of flights \\
\hline$o n_{i}, d n_{i}$ & Origin and destination of flight $i$ \\
\hline$d s_{i}$ & Distance between the origin and destination of flight $i$ \\
\hline$p_{i j}$ & $=1$, if flight $i$ and $j$ have common passengers and 0 , otherwise \\
\hline$s t{ }_{d}, f t{ }_{d}$ & Start and finish times of day $d$ \\
\hline $\mathrm{stm}_{d}, \mathrm{ftm}{ }_{d}$ & Interval times to start the maintenance on day $d$ \\
\hline${ }^{s p}{ }_{t l}$ & Amount of speed level $l$ for aircraft $t$ \\
\hline$s p_{i t}^{\min }, s p_{i t}^{\max }$ & Minimum and maximum speed of aircraft $t$ for flight $i$ \\
\hline${ }^{T P}{ }_{i j}$ & Turnaround time, time needed to connect passengers from flight $i$ to flight $j$ \\
\hline${ }^{T A}{ }_{i j t}$ & Turntime, time needed to prepare aircraft $t$ between flights $i$ and $j$ \\
\hline$E\left[N C{ }_{i}\right]$ & Expected non-cruise time for flight $i$ \\
\hline$E\left[R M_{i}\right]$ & Expected ramp service time for flight $i$ \\
\hline$\lambda_{t}$ & Maximum available cruise time of aircraft $t$ on a day \\
\hline$P M_{t}$ & Duration time of maintenance type A for aircraft $t$ \\
\hline$\delta_{t}$ & Maximum flight time between successive maintenance type A for aircraft $t$ \\
\hline $\operatorname{Dem}_{i}$ & Passengers' demand for flight $i$ \\
\hline $\mathrm{Cap}_{t}$ & Seat capacity for aircraft $t$ \\
\hline$C_{s p l}{ }_{i}$ & Opportunity cost of spilled passengers for flight $i$ \\
\hline Daily $_{t}$ & Daily cost when aircraft $t$ is used \\
\hline$c_{\text {fuel }}, c_{\mathrm{CO}_{2}}$ & Fuel cost and $\mathrm{CO}_{2}$ emission cost in kgs \\
\hline$c_{m n t}$ & Fixed cost to perform maintenance type A \\
\hline cstup $_{d n_{i}}$ & Set up cost for maintenance type A at destination of flight $i$ \\
\hline$\gamma$ & Cruise flight time cost \\
\hline$\partial_{i}$ & Daily postponement cost to perform flight $i$ \\
\hline$e f c_{t}$ & Efficiency of aircraft $t$ \\
\hline bigM & A big number \\
\hline
\end{tabular}


$\tau \quad \mathrm{CO}_{2}$ emission per kg of energy consumption.

\section{Decision variables}

$$
\begin{aligned}
& e_{t d}^{e} \quad=1 \text {, if aircraft } t \text { performs more than one flight on day } d \text { and } 0 \text {, otherwise } \\
& v_{i t d} \quad=1 \text {, if aircraft } t \text { performs flight } i \text { on day } d \text { and } 0 \text {, otherwise }
\end{aligned}
$$

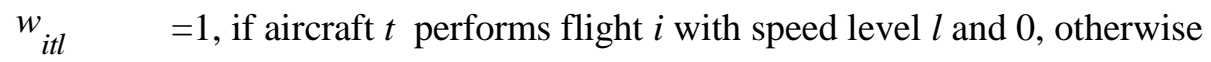

$$
\begin{aligned}
& x_{i j t d}=1 \text {, if aircraft } t \text { performs flight } i \text { and } j \text { consecutively on day } d \text { and } 0 \text {, otherwise }
\end{aligned}
$$

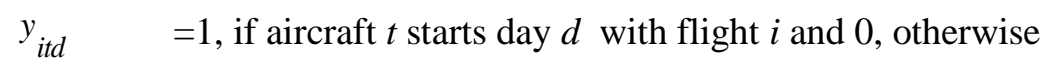

$$
\begin{aligned}
& z_{i t d} \quad=1 \text {, if aircraft } t \text { finishes day } d \text { with flight } i \text { and } 0 \text {, otherwise } \\
& q_{t d} \quad=1 \text {, if aircraft } t \text { gets maintenance type A on day } d \text { and } 0 \text {, otherwise } \\
& \sigma_{t d} \quad=0 \text {, if aircraft } t \text { performs one flight on day } d \text { and a nonnegative number, otherwise } \\
& d p_{i}, a r_{i} \quad \text { Departure and arrival times for flight } i \\
& f_{i t} \quad \text { Cruise time for flight } i \text { with aircraft } t \\
& \eta_{t d} \quad \text { Total cruise flight time for aircraft } t \text { until the end of the day } d \\
& \text { STM }_{i d} \quad \text { Start time of maintenance type A on aircraft } t \text { on day } d \text {. }
\end{aligned}
$$

Now, the bi-objective MINLP model is as follows:

$$
\begin{gathered}
\operatorname{Min}\left[\sum_{i \in F} \sum_{t \in T} \sum_{l \in L}\left(\frac{c_{\text {futel }}+\tau \times c_{c o_{2}}}{e f c_{t}}\right) \times F_{i}\left(f_{i t}\right) \times w_{i t l}+\sum_{i \in F} \sum_{t \in T} \sum_{d \in D} \text { Daily }_{t} \times y_{i t d}\right. \\
\left.+\sum_{t \in T} \sum_{d \in D} c_{m n t} \times q_{t d}+\sum_{i \in F} \sum_{t \in T} \sum_{d \in D} c s t u p_{d n_{i}} \times q_{t d} \times z_{i t d}\right], \\
\operatorname{Min}\left[\sum_{i \in F} \sum_{t \in T} \sum_{l \in L} \gamma \times \frac{d s_{i}}{s p_{t l}} \times w_{i t l}+\sum_{i \in F} \sum_{t \in T} \sum_{d \in D} \partial_{i} \times(d-1) \times v_{i t d}+\sum_{i \in F} \sum_{t \in T} \sum_{d \in D} C s p l_{i} \times \max \left(0, \text { Dem }_{i}-\text { cap }_{t}\right) \times v_{i t d}\right],
\end{gathered}
$$

S.t.

$$
\begin{array}{cc}
\sum_{t \in T} \sum_{d \in D} v_{i t d}=1, & \forall i \in F \\
\sum_{j \in F} \sum_{t \in T} \sum_{d \in D} x_{i j t d} \leq 1, & \forall i \in F \\
\sum_{i \in F} \sum_{j \in F(j \neq i)} x_{i j d}=\sum_{i \in F} v_{i t d}-1, & \forall t \in T, d \in D \\
\sum_{i \in F(i \neq j)} x_{i j d d}+\sum_{i \in F(i \neq j)} x_{j i t d} \leq 2 \times v_{j t d}, & \forall j \in F, t \in T, d \in D \\
\sum_{i \in F} v_{i t d} \leq b i g M \times e_{t d}, & \forall t \in T, d \in D
\end{array}
$$




$$
\begin{aligned}
& \sum_{i \in F M} y_{i t d}=e_{t d}, \quad \forall t \in T, d \in D \\
& \sum_{i \in F M_{i}} z_{i d d}=e_{t d}, \quad \forall t \in T, d \in D \\
& y_{i t d} \leq v_{i t d}-\sum_{j \in F} x_{j i t d}, \quad \forall i \in F, t \in T, d \in D \\
& z_{i t d} \leq v_{i t d}-\sum_{j \in F} x_{i j t d}, \quad \forall i \in F, t \in T, d \in D \\
& \sum_{i \in F} v_{i t d}-1 \leq(N(F)-1) \times \sigma_{t d}, \quad \forall t \in T, d \in D \\
& y_{i t d}+z_{i t d} \leq 2-\sigma_{t d}, \quad \forall i \in F, t \in T, d \in D \\
& y_{\text {itd }} \leq v_{\text {itd }}, \quad \forall i \in F, t \in T, d \in D \\
& z_{\text {itd }} \leq v_{\text {itd }}, \quad \forall i \in F, t \in T, d \in D \\
& \sum_{j \in u_{i}} y_{j t(d+1)}=z_{i t d}, \quad \forall i \in F, t \in T, d \in D / d_{l t} \\
& d p_{i} \geq \sum_{d \in D} s t_{d} \times v_{i d d}+E\left[N C_{i}\right]+E\left[R M_{i}\right], \quad \forall i \in F, t \in T \\
& a r_{i} \leq \sum_{t \in T} \sum_{d \in D} f t_{d} \times v_{i d d}, \quad \forall i \in F \\
& a r_{i}=d p_{i}+\sum_{i \in T} \sum_{d \in D} f_{i t} \times v_{i t d}, \quad \forall i \in F \\
& \sum_{l \in L} w_{i t l}=\sum_{d \in D} v_{i t d}, \quad \forall i \in F, t \in T \\
& s p_{i t}^{{ }_{i t}^{\min }} \leq s p_{t l} \times w_{i t l} \leq s p_{i t}^{\max }, \quad \forall i \in F, t \in T, l \in L \\
& f_{i t}=\sum_{l \in L} \frac{d s_{i}}{s p_{t l}} \times w_{i t l}, \quad \forall i \in F, t \in T \\
& d p_{j} \geq a r_{i}+T P_{i j}+E\left[N C_{i}\right]+E\left[N C_{j}\right] \\
& +E\left[R M_{i}\right]+E\left[R M_{j}\right]-\operatorname{big} M \times\left(1-p_{i j}\right), \\
& d p_{j} \geq a r_{i}+\sum_{t \in T} \sum_{d \in D} T A_{i j t} \times v_{i t d}+E\left[N C_{i}\right]+E\left[N C_{j}\right] \\
& +E\left[R M_{i}\right]+E\left[R M_{j}\right]-\operatorname{bigM} \times\left(1-\sum_{i \in T} \sum_{d \in D} x_{i j d d}\right), \\
& \sum_{i \in F} f_{i t} \leq \lambda_{t} \\
& \eta_{t d}=\sum_{i \in F} \sum_{k \in D(k \leq d)} f_{i t} \times v_{i t k} \\
& 0 \leq \eta_{t d}-\delta_{t} \times \sum_{k \in D(k \leq d)} q_{d k} \leq \delta_{t}, \\
& s t m_{d} \leq S T M{ }_{d d} \leq \mathrm{ftm}_{d}, \\
& a r_{i} \leq S T M_{t d}+b i g M \times\left(2-q_{t d}-v_{i d d}\right), \\
& d p_{i} \geq S T M_{t(d-1)}+p m_{t}-\operatorname{big} M \times\left(2-q_{t(d-1)}-v_{i d d}\right), \\
& e_{t d}, v_{i t d}, w_{i t t}, x_{i t d d}, y_{i t d}, z_{i t d}, q_{t d} \in\{0,1\} \\
& \forall i, j_{(i \neq j)} \in F \\
& \forall i, j_{(i \neq j)} \in F \\
& \forall t \in T \\
& \forall i \in F, d \in D \\
& \forall t \in T, d \in D \\
& \forall t \in T, d \in D \\
& \forall i \in F, t \in T, d \in D \\
& \forall i \in F, t \in T, d \in D
\end{aligned}
$$




$$
\sigma_{t d}, d p_{i}, a r_{i}, f_{i t}, \eta_{t d}, S T M_{t d} \geq 0, \quad \forall i \in F, t \in T, d \in D
$$

Note that objective (1) consists of four terms. The first term is an estimate of energy consumption and amount of $\mathrm{CO}_{2}$ emission. The TEC estimation is similar to the fuel burn function of Aktürk et al. [3]. TEC is calculated as follows:

$$
F_{i}\left(f_{i t}\right)= \begin{cases}c_{1}^{i, t} \times \frac{1}{f_{i t}}+c_{2}^{i, t} \times \frac{1}{f_{i t}^{2}}+c_{3}^{i, t} \times f_{i t}^{3}+c_{4}^{i, t} \times f_{i t}^{2}, & \text { if } v_{i t d}=1 \\ 0, & \text { if } v_{i t d}=0,\end{cases}
$$

Where the coefficients $c_{1}^{i . t}, c_{2}^{i . t}, c_{3}^{\text {i.t }}$ and $c_{4}^{\text {i.t }}$ correspond to the aircraft properties $[3,18]$. The coefficients are different for each aircraft and each route. We propose using $e f c_{t}$ in the first objective which leads to using the high performance aircrafts more. Lee [27] studied the effect of aircraft system on energy consumption. The study noted three criteria including aircraft structure, aerodynamic feature and engine efficiency affecting the aircraft efficiency. Engine efficiency is defined by the ratio of power to the energy consumption. Therefore, aircraft efficiency affect TEC. The above criteria due to engine material, engine weight, engine size, wing design, engine peak pressure, engine temperature and cooling system are different for each aircraft type. So, aircraft efficiency is different for various aircrafts. Considering the aircraft efficiency is unavoidable to reduce the energy consumption. For example, old aircrafts due to their overuse are depreciating. They need more maintenance. In this case, the aircraft fuel efficiency decreases and its use cost increases. A solution for having a better fuel efficiency is to purchase new aircrafts concurring fundamental costs. The price to buy an aircraft ranges from 80 to 400 million dollars [6]. Another solution for aircraft efficiency is to take maximal use of highly-efficient aircrafts and minimal use of low-efficient aircrafts. In this way, we have a better TEC without any extra fundamental costs. The second term in (1) is concerned with the daily use of the aircrafts. Due to the differences in aircraft efficiencies and their ages, the daily cost of using each aircraft is different. The proposed model tries to make a maximal use of highly-efficient aircrafts to decrease the daily use cost. The third and fourth terms in (1) calculate the cost of maintenance. The maintenance includes the fixed and the set up costs. The MINLP model reduces the number of maintenances in decreasing the fixed cost. The set up cost is different in each airport. The proposed model tries to route in such a way that maintenance be performed in airports having lower costs. Objective (2) calculates PSL. It consists three terms. The first term controls the cruise flight time with CSC. We divide the time into two parts. The first part is called cruise flight time, and the second one is called non-cruise time and ramp service time. Cruise flight time includes the time between the takeoff and landings of the aircrafts. Non-cruise time includes the time related to taxi-in, taxi-out, climbing and descending stages, and ramp service time includes the guiding of aircraft to the parking lot, refueling the aircraft, luggage handling and air cargo handling. We have considered the cruise flight time as one of the PSL measurements. Three viewpoints support our choice.

First: Hussain et al. [23] pointed 5 dimensions affecting service quality. They include reliability, security and safety, responsiveness, assurance and tangibility. According to this study, reliability contains flight punctuality and reaching the destination within the promised time. Proper scheduling can lead to punctuality. Cruise flight time is a sensitive factor for scheduling. If cruise time changes for a flight, then other flight scheduling will change. So, cruise flight time affects punctuality and reliability. 
Second: Probability of air accident such as mid-air collisions and total loss of flight control is equal to $1.55 \times 10^{-8}$ in a flight hour [34]. It is understandable that if the cruise flight time decreases, then the accident risk decreases and safety of flights increases. As mentioned above, security and safety affect service quality.

Third: One of the most important features of airline industry is saving travel time. Gronau [17] showed it to be an important factor for passenger satisfaction.

Because of the above three viewpoints, we have decided to bring up the cruise flight time as a PSL measurement. The first term in (2) tries to minimize the cruise flight time. This leads to maximizing PSL and minimizing its related cost through the parameter $\gamma\left(\gamma=1.55 \times 10^{-8}\right)$. We consider the flight day as another measurement for PSL. Schedule design tries to start flights as soon as possible [8]. A proper schedule design can be a competitive advantage in the airline industry, increasing the passengers' satisfaction. Usually, passengers choose a service provider who plans flights at the earliest time. The second term in (2) tries to minimize the days of flying. Minimizing the days of flying maximizes PSL and minimizes its related cost through parameter $\partial$. We consider a penalty cost $(\partial)$ for each daily postponed flight. The third term in (2) tries to minimize the missed demands.

Constraint (3) assigns only one aircraft and one day to each flight. If a flight destination is the same as origin of another flight, then one aircraft performs these flights consecutively. Constraints (4), (5) and (6) allow some flights to schedule this way. Multiday planning and maintenance consideration have made it necessary to identify the first and last flights of aircrafts in each day. We have used a new approach for this identification which is referenced by constraints (7)-(15). Constraints (7), (8) and (10) find the first flight for each aircraft in each day. Also, constraints (7), (9) and (11) find the last flight for each aircraft in each day. Constraint (12) determines $\sigma_{t d}$. If different flights are made by aircraft $t$ on day $d$, then $\sigma_{t d}>0$. In this case, constraint (13) does not allow a flight to be considered as the first and last flight at the same time. If aircraft $t$ makes only one flight on day $d$, then $\sigma_{t d}=0$. In this case, constraint (13) considers this flight as the first and the last flight at the same time. Constraints (14) and (15) state that if flight $i$ is not performed by aircraft $t$, then this flight cannot be considered as the first or last flight for aircraft $t$. Constraint (16) is a necessity to identify the first and last flights of aircrafts in each day. For every aircraft, this constraint ensures that the last destination in a day is the same as the first origin in the next day. There is a limit on arrival and departure times of flights due to the curfew time [22]. Constraints (17) and (18) apply this limit. Constraint (19) controls the relation between departure and arrival times for each flight. According to the assumptions, each aircraft selects only one speed level during the cruise flight. Constraint (20) selects this speed level. Constraint (21) limits the aircraft speed level according to the fuel tank capacity in such a way that aircraft fuel does not end before arrival to destination. Constraint (22) calculates the cruise flight time by considering the cruise speed control. There is a need to take some time to prepare the aircraft for consecutive flights (turntime) and consider the connection times for flights with common passengers (turnaround time). Therefore, there is a relation between a flight departure time and other flights arrival times. Constraints (23) and (24) control this relation. Constraint (25) considers the time limit for aircraft use in each day. Constraint (26) calculates the total cruise flight time by each aircraft in each day. According to this time, constraint (27) checks whether the maintenance is needed or aircraft can perform the next flight. In other words, maintenance should be performed every $\delta_{t}$ hours. Constraint (28) determines the start time of maintenance which should be within the allowed period of time. Constraints (29) and (30) identify the first and last flights of aircrafts in each day. If aircraft $t$ needs maintenance on day $d$, then all assigned flights to aircraft $t$ on day $d$ must be completed before the start time of maintenance. Also, departure time of next flights assigned to the aircraft $t$ 
should be made after finish time of the maintenance. Constraints (29) and (30) attend to these limits. Constraints (31) and (32) represent the binary and nonnegative variables, respectively.

\subsection{Linearization}

The model is nonlinear due to $q_{t d} \times z_{i t d}$ and $f_{i t} \times v_{i t d}$. We define new variable $q z_{i t d}$ as $q z_{i t d}=$ $q_{t d} \times z_{i t d}$. The following constraints are defined to linearize $q_{t d} \times z_{i t d}$ :

$$
\begin{array}{cl}
q z_{i t d} \leq q_{t d}, & \forall i \in F, t \in T, d \in D \\
q z_{i t d} \leq z_{i t d}, & \forall i \in F, t \in T, d \in D \\
q z_{\text {itd }} \geq z_{i t d}+q_{t d}-1, & \forall i \in F, t \in T, d \in D \\
q z_{i t d} \geq 0, & \forall i \in F, t \in T, d \in D .
\end{array}
$$

By defining these four constraints, $q_{t d} \times z_{i t d}$ is converting to linear relations. This linearization approach is similar to the one given by Norouzi et al. [31].

We define new variable $f v_{i t d}$ as $f v_{i t d}=f_{i t} \times v_{i t d}$. The following constraints are defined to linearize $f_{i t} \times v_{i t d}$ :

$$
\begin{array}{cc}
\sum_{d \in D} f v_{i t d} \leq f_{i t}, & \forall i \in F, t \in T \\
f v_{i t d} \leq b i g M \times v_{i t d}, & \forall i \in F, t \in T, d \in D \\
\sum_{d \in D} f v_{i t d} \geq f_{i t}-b i g m \times\left(1-\sum_{d \in D} v_{i t d}\right), & \forall i \in F, t \in T \\
f v_{i t d} \geq 0, & \forall i \in F, t \in T, l \in L .
\end{array}
$$

By defining these four constraints, $f_{i t} \times v_{i t d}$ is converting to linear relations. This linearization approach is similar to the one proposed by Glover and Woolsey [16].

\subsection{Distribution of Parameters}

Uncertainty in air transport appears in noncruise time and ramp service time. The predicted values for these parameters may be too far from their exact values due to possible airport congestions. One approach to overcome the uncertainty associates with expected value of these parameters. Şafak et al. [33] considered the Log-Laplace distribution to be a good-fit to the noncruise time. Duran et al. [12] provided the expected value of Log-Laplace distribution as follows:

$$
E\left[N C_{i}\right]=\frac{e^{\alpha}}{\left(1-\beta_{i}\right) \times\left(1+\beta_{i}\right)}, \quad \forall i \in F,
$$

Where $e^{\alpha}$ is a constant which is used to estimate the mean and variance of the non-cruise time. The value of $e^{\alpha}$ is taken to be 15 to have a non-cruise time deviating from 15 minutes. Also, $\beta_{i}$ is defined to estimate the airport congestion: 


$$
\beta_{i}=\beta \times E_{o n_{i}}^{2} \times E_{d n_{i}}^{2}, \quad \forall i \in F
$$

Where $\beta$ is a constant, $E_{o n_{i}}$ and $E_{d n_{i}}$ are the congestion coefficients respectively for the origin and destination of flight $i$.

Similar to the above, we use Log-Laplace distribution for ramp service time. Therefore, its expected value is calculated as follows:

$$
E\left[R M_{i}\right]=\frac{e^{\varphi}}{\left(1-\beta_{i}\right) \times\left(1+\beta_{i}\right)}, \quad \forall i \in F
$$

Where $e^{\varphi}$ is a constant which is used to estimate the mean and variance of the ramp service time. The value of $e^{\varphi}$ is taken to be 20 to have a ramp service time deviating from 20 minutes.

Airport congestion affects the turntime and duration time of maintenance which are calculated as follows:

$$
\begin{array}{cl}
T A_{i j t}=\text { baseturnti me } \times E_{d n_{i}}, & \forall i \in F, \\
p m_{t}=\text { basemainte nacetime } \times E_{d n_{i}}, & \forall i \in F,
\end{array}
$$

Where baseturntime and basemaintenacetime are respectively base time for turntime and duration time for maintenance type A.

\subsection{Solution Method}

For simplicity, $f_{1}$ and $f_{2}$ are defined as the first objective (1) and second objective (2):

$$
\begin{aligned}
& f_{1}=\left[\sum_{i \in F} \sum_{t \in T} \sum_{l \in L}\left(\frac{c_{f t u e l}+\tau \times c_{c o_{2}}}{e f c_{t}}\right) \times F_{i}\left(f_{i t}\right) \times w_{i t l}+\sum_{i \in F} \sum_{t \in T} \sum_{d \in D} \text { Daily }_{t} \times y_{i t d}+\sum_{t \in T} \sum_{d \in D} c_{m n t} \times q_{t d}\right. \\
& \left.+\sum_{i \in F} \sum_{t \in T} \sum_{d \in D} \operatorname{cstup}_{d n_{i}} \times q_{t d} \times z_{i d d}\right] \\
& f_{2}=\left[\sum_{i \in F} \sum_{t \in T} \sum_{l \in L} \gamma \times \frac{d s_{i}}{s p_{t l}} \times w_{i t}+\partial \times \sum_{i \in F} \sum_{t \in T} \sum_{d \in D}(d-1) \times v_{i d d}+\sum_{i \in F} \sum_{t \in T} \sum_{d \in D} C s p l_{i} \times \max \left(0, \text { Dem }_{i}-c a p_{t}\right) \times v_{i d d}\right] .
\end{aligned}
$$

Then, the proposed model in Section 3.1 is rewritten as follows:

Problem $P$ :

$$
\begin{gathered}
\text { Min } f_{1} \\
\text { Min } f_{2} \\
\text { S.t. } \\
(3)-(32),(34)-(41) \text {. }
\end{gathered}
$$


Multiobjective problems, unlike single-objective problems, may not achieve optimal solutions. In multiobjective problems, non-dominated solutions replace optimal solutions [30]. There are some popular techniques for multiobjective problems including weighted-sum and $\varepsilon$-constraint methods. Mavrotas [30] gave a comparison of these two methods, as summarized in Table 1.

Table 1. Comparison of weighted-sum and $\varepsilon$-constraint methods for multiobjective problems.

\begin{tabular}{cc}
\hline Weighted-sum method & $\varepsilon$-constraint method \\
\hline Generates only extreme solutions & Generate extreme and non-extreme solutions \\
Many redundant runs lead to the same solution & Each run leads to a different solution \\
It is necessary to scale the objectives & It is not necessary to scale the objectives \\
It is hard to control the number of solutions & It is easy to control the number of solutions \\
\hline
\end{tabular}

Besides the above advantages of the $\varepsilon$-constraint method, Mavrotas [30] noted some disadvantages for the method. These include the range calculation of the objectives over the efficient set and production of dominated or weakly non-dominated solutions. Mavrotas [30] offered techniques to overcome these challenges which eventually led to the augmented $\varepsilon$-constraint method. Here, we briefly explain the steps of the augmented $\varepsilon$-constraint method for the minimization problem:

1. Create payoff table to calculate the range of each objective,

2. Define number of grid points $\left(g_{k}\right)$ to divide each objective into $g_{k}+1$ equal ranges,

3. Consider one objective as the main objective and the others as constrained objectives,

4. Solve the problem $P_{\text {aug-eps }}$ below for dividing ranges.

We consider objective (1) as the main objective in the augmented $\varepsilon$-constraint method and objective (2) as the constrained objective.

Problem $P_{\text {aug-eps }}$ :

$$
\begin{gathered}
\operatorname{Min} f_{1}+\varepsilon\left(\frac{s_{2}}{r_{2}}\right) \\
\text { s.t. } \\
f_{2}+s_{2}=e_{2} \\
(3)-(32),(34)-(41),
\end{gathered}
$$

Where $e_{2}=u b_{2}-\left(\frac{i t r \times r_{2}}{g_{2}}\right), u b_{2}$ and $r_{2}$ are respectively the upper bound and the range of objective (2), $\varepsilon$ is a very small number $\left(10^{-3}\right.$ to $\left.10^{-6}\right), s_{2}$ and itr are a non-negative surplus variable and the iteration number, respectively. For detailed explanations, we refer the interested reader to Mavrotas [30].

\subsection{Conflicting Objectives}

We consider a multiday planning bi-objective optimization model with a conflict between its two objectives. CSC provides interaction between TEC and PSL. We comply with a set of flight information. The information is publicly available through the Emirates flights (http://www.emirates.com). The flights were performed on 24 November, 2016. Table 2 shows the published schedule from the Emirates flights. 
Table 2. Published schedule of Emirates flights

\begin{tabular}{cccccc}
\hline Flight number & From & To & Departure time & Cruise time (hours) & Aircraft \\
\hline EK 975 & DXB & IKA & $2: 25$ & 2.15 & Boeing 777-300ER \\
EK 976 & IKA & DXB & $5: 40$ & 2.10 & Boeing 777-300ER \\
EK 971 & DXB & IKA & $7: 50$ & 2.20 & Boeing 777-300ER \\
EK 972 & IKA & DXB & $10: 55$ & 2.10 & Boeing 777-300ER \\
EK 322 & DXB & ICN & $3: 30$ & 8.20 & Airbus A380 \\
EK 323 & ICN & DXB & $13: 50$ & 10.10 & Airbus A380 \\
EK 143 & DXB & MAD & $14: 40$ & 8.10 & Boeing 777-300ER \\
EK 144 & MAD & DXB & $23: 10$ & 7.00 & Boeing 777-300ER \\
\hline
\end{tabular}

Two aircrafts made eight different flights. Although some flights have the same origin and the same destination, but their cruise flight times were different. This is due to the different aircraft speed levels. Here, it is possible to change the cruise flight time by CSC. This gives managers more flexibility to survey different plans which may not be possible in a constant speed mode [18]. We applied our model to the flights in Table 2. Fig. 1 shows the results.

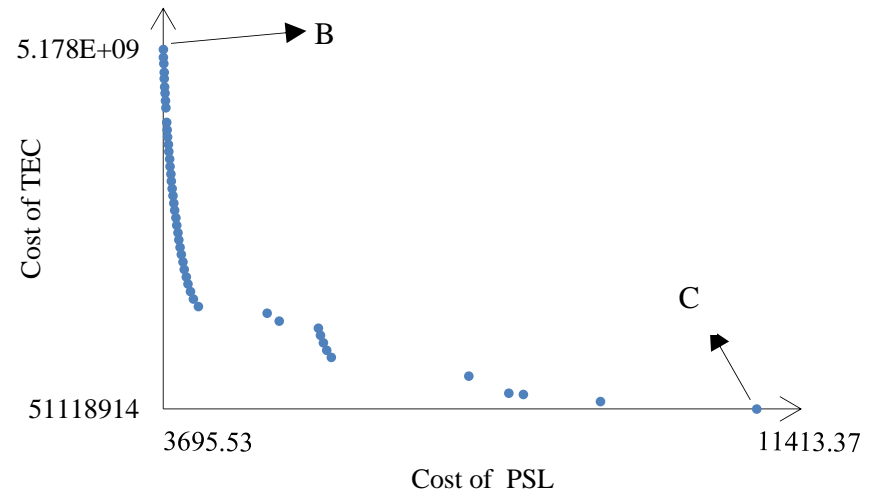

Figure 1. Obtained Pareto solutions for the mentioned example

The model obtained different Pareto solutions. Each Pareto has its own sequence with particle departure and arrival times and maintenance consideration. In Pareto B, TEC is at its highest cost since all flights were made by the fastest speed levels. This puts PSL at its best value because cruise flight time was minimized. One of the important criteria in marketing is customer satisfaction [21] which is a key factor for customer loyalty. In this Pareto solution, passengers receive a high service level but the cost of energy is at its worst. So, we have a high energy cost in this Pareto solution. In this situation, managers are forced to increase the ticket price to create a balance between cost and revenue. Passengers prefer to spend less money beside higher service level [20]. Increasing customer satisfaction needs a higher service level compared with the cost they spend in reality. This achieves a high perceived service value. As defined by Hapsari et al. [20], perceived value measures the benefit and cost the customer perceives. The time is preferred to the cost in Pareto B. If managers decide to decrease the cost, then the aircraft speed should be reduced. Whatever we get closer to Pareto C, energy consumption decreases since flights are made with the lowest speed levels. This causes the cost to decrease. In this situation, PSL is at its worst value and TEC is at its own best. In this Pareto solution, cost is preferred to time.

Choosing any of these Pareto solutions depends on the corporate policies. Some factors influence decision making. These factors include passenger flow and restriction on $\mathrm{CO}_{2}$ emission. Each aircraft uses multiple airports some of which are crowded and others are not. Choosing a fast 
speed for flights with origin or destination being crowded can lead to faster flow. Therefore, it is critical to consider passenger flow to choose the speed level. Also, in some countries, there are restrictions on fuel consumption and $\mathrm{CO}_{2}$ emission which should be considered by managers. Based on these factors, managers choose a Pareto solution. There are several approaches to help decision makers to choose one solution among different Pareto solutions. One method is weighting objectives using analytical hierarchy process (AHP). This method combines objectives based on the weights to form a single-objective. Then, an optimal value is decided. In another method, the desirable value of each objective is asked from the decision maker. In this way, an ideal point is found. Distances between Pareto solutions and the ideal point are calculated, and the shortest distance is selected. There are some other approaches. Some studies like Cheikh et al. [7], Taboada et al. [35] and Malakooti and Raman [29], developed a clustering approach for choosing one solution. From all these approaches, we select the TOPSIS (Technique for Order of Preference by Similarity to Ideal Solution) technique to choose a solution. Hwang and Yoon [24] proposed TOPSIS. Algorithm 1 shows this procedure. 


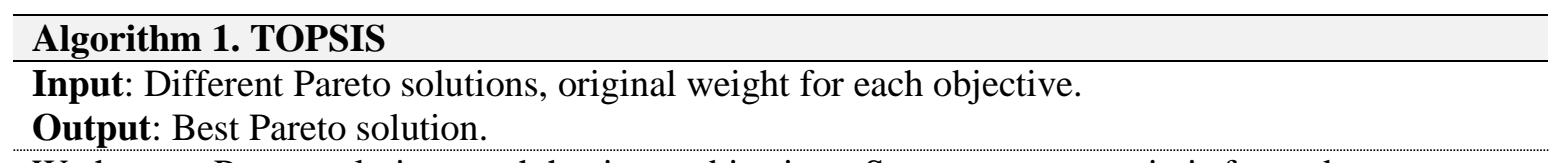
We have $m$ Pareto solutions each having $n$ objectives. So, an $m \times n$ matrix is formed. All values in this matrix are normalized.

Let $f_{a b}$ and $n_{a b}$ denote the value of objective $b(1 \leq b \leq n)$ in Pareto solution $a(1 \leq a \leq m)$ and normalize the value of objective $b$ in Pareto solution $a$ :

$$
n_{a b}=\frac{f_{a b}}{\sqrt{\sum_{a=1}^{m} f_{a b}^{2}}}, \quad \forall a, \forall b,
$$

Calculate normalized weights for all the objectives in all Pareto solutions.

Let $w_{b}$ and $\vartheta_{a b}$ denote the original weights for the objective $b$ and normalized weight for the objective $b$ in Pareto solution $a$, respectively. Compute:

$$
\vartheta_{a b}=w_{b} \times n_{a b}, \quad \forall a, \forall b,
$$

Find positive ideal $\left(A^{+}\right)$and negative ideal $\left(A^{-}\right)$solutions.

Let $t_{n}^{+}$and $t_{n}^{-}$denote the best and the worst value of the objective $b$, respectively.

$$
\begin{aligned}
& A^{+}=\left\{\min _{a}\left(\vartheta_{a b} \mid b \in n\right)\right\} \equiv\left(t_{1}^{+}, t_{2}^{+}, \ldots, t_{n}^{+}\right), \\
& A^{-}=\left\{\max _{a}\left(\vartheta_{a b} \mid b \in n\right)\right\} \equiv\left(t_{1}^{-}, t_{2}^{-}, \ldots, t_{n}^{-}\right) .
\end{aligned}
$$

Calculate Euclidean distance of each Pareto solution from positive ideal solution $\left(d_{a}^{+}\right)$and negative ideal solution $\left(d_{a}^{-}\right)$:

$$
\begin{aligned}
& d_{a}^{+}=\sqrt[2]{\sum_{b=1}^{n}\left(\vartheta_{a b}-t_{b}^{+}\right)^{2}}, \\
& d_{a}^{-}=\sqrt[2]{\sum_{b=1}^{n}\left(\vartheta_{a b}-t_{b}^{-}\right)^{2}},
\end{aligned}
$$

$\forall a$.

Calculate the relative closeness of each Pareto solution.

Let $R_{a}$ denote the relative closeness of pareto solution $a\left(0 \leq R_{a} \leq 1\right)$ and compute:

$$
R_{a}=\frac{d_{a}^{-}}{d_{a}^{+}+d_{a}^{-}}, \quad \forall a .
$$

Sort $R_{a}$ in descending order.

Choose the value closet to 1 as the best pareto solution.

Report Best Pareto solution

The more $R_{a}$ is closer to 1 , the shorter distance the selected solution has from the positive ideal solution and the longer distance it has from the negative ideal solution. Fig. 1 shows the different non-dominated solutions. We applied TOPSIS to the solutions and calculated the relative closeness of all Pareto solutions. Fig. 2 shows the result. 


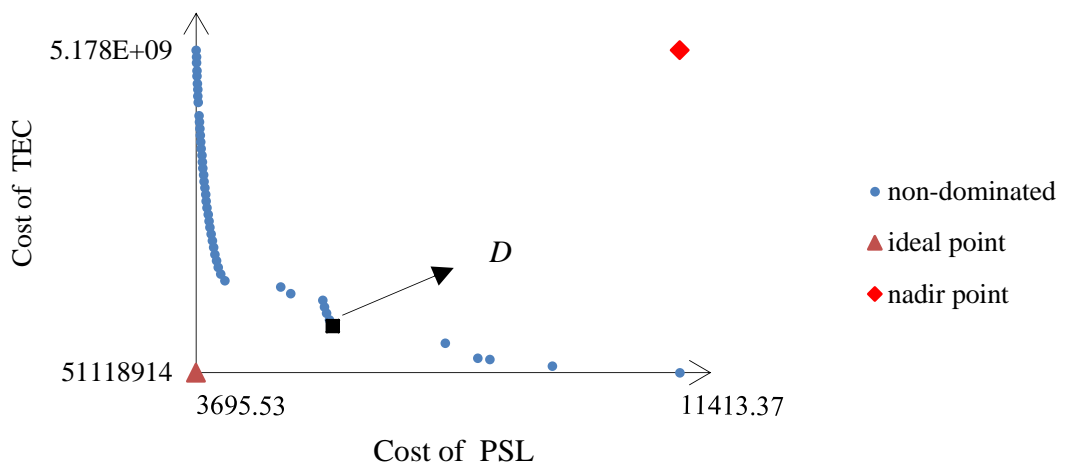

Figure 2. Best solution for the mentioned example

Optimal and worst value of objectives (1) and (2) are considered in Fig. 2. Ideal point represents the optimal value corresponding to the objectives (1) and (2), and nadir point represents the worst value corresponding to the objectives (1) and (2). The ideal solution is not available because the two objectives are considered simultaneously. There is no difference between the objectives (1) and (2). So, their original weight is considered to be the same. TOPSIS found Pareto D. Table 3 shows the proposed schedule by the model for Pareto D.

Table 3. Proposed schedule

\begin{tabular}{cccccc}
\hline Flight number & From & To & Departure time & Cruise time (hour) & Aircraft \\
\hline EK 975 & DXB & IKA & $1: 00$ & 1.55 & Boeing 777-300ER \\
EK 976 & IKA & DXB & $8: 25$ & 1.33 & Airbus A380 \\
EK 971 & DXB & IKA & $6: 10$ & 1.40 & Airbus A380 \\
EK 972 & IKA & DXB & $3: 20$ & 1.45 & Boeing 777-300ER \\
EK 322 & DXB & ICN & $10: 40$ & 8.00 & Airbus A380 \\
EK 323 & ICN & DXB & $19: 20$ & 7.50 & Airbus A380 \\
EK 143 & DXB & MAD & $5: 30$ & 8.10 & Boeing 777-300ER \\
EK 144 & MAD & DXB & $14: 10$ & $7: 20$ & Boeing 777-300ER \\
\hline
\end{tabular}

We noted that the model proposed a new schedule as compared to the published schedule. Main changes include schedule design, aircraft assignment and maintenance routing. Fig. 3 shows these two different schedules. The changes are due to the TEC and PSL considerations. CSC can reach different speed levels. Each speed level leads to a different energy consumption. Equation (33) calculates the energy consumption. Based on this equation, energy consumption is related to the cruise flight time. According to constraint (22), there is a relation between cruise flight time and aircraft speed level. Therefore, the speed level affects the energy consumption and $\mathrm{CO}_{2}$ emission. Also, some factors such as aircraft properties, aerodynamic features and aircraft's ages affect the coefficients $c_{1}^{i . t}, c_{2}^{i . t}, c_{3}^{i . t}$ and $c_{4}^{\text {i.t }}$ in equation (33). These coefficients are different for each aircraft and are published in EUROCONTROL [13] for 399 different aircraft types. Therefore, besides the speed level, aircraft efficiency affects fuel consumption. Aktürk et al. [3] showed the energy consumption increases with higher speed levels. Fig. 1 also confirms this. The highest speed level in Pareto $\mathrm{B}$ leads to the maximum energy consumption. As the speed decreases, the energy consumption decreases. In Pareto C, all flights are made with the lowest speed level leading to the lowest energy consumption. 


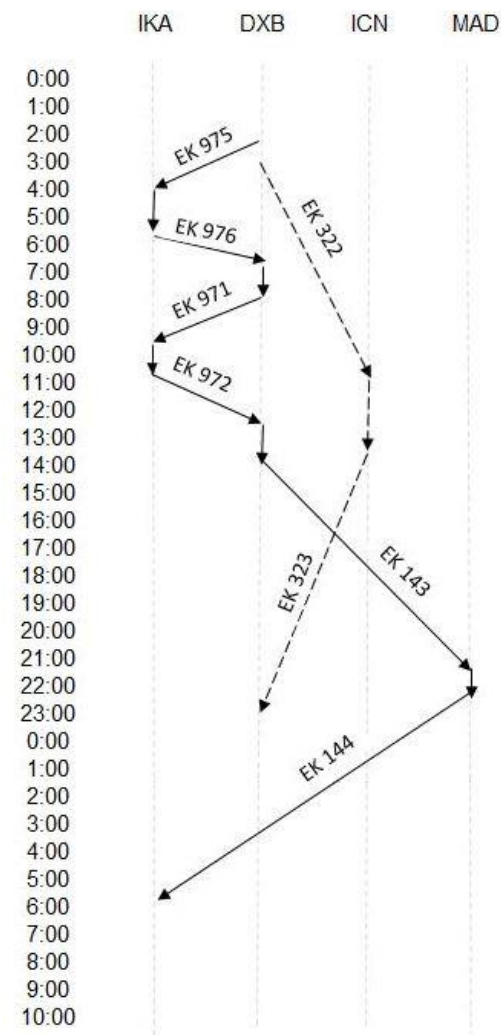

(a) Published schedule

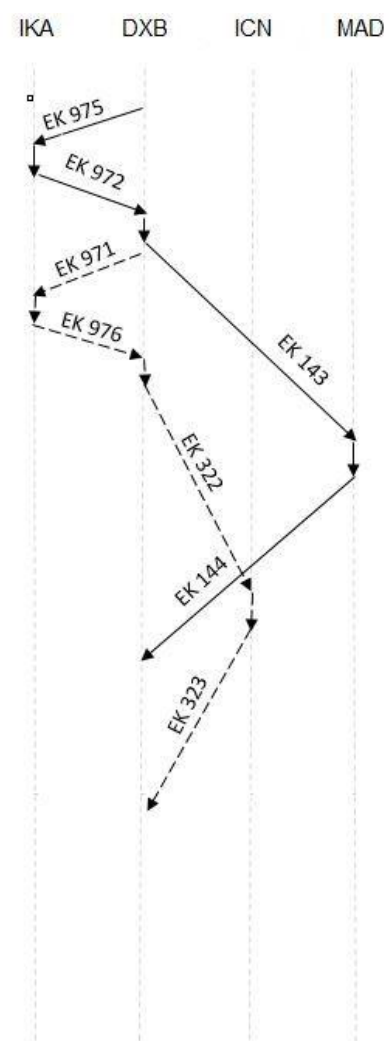

(b) Proposed schedule

Figure 3. Comparing proposed schedule and published schedule

In Fig. 3 , vertical lines represent noncruise time, ramp service time, turnaround time, turntime and maintenance time, and Diagonal lines represent cruise flight time. In the next section, we present different test problems based on real data to evaluate the effectiveness of proposed model. The results are compared using various scenarios.

\section{Computational Results and Analysis}

Here, we present computational results to evaluate the model. We experimented with the model using the augmented $\varepsilon$-constraint method implemented in GAMS V.24.1.3. The test problems were solved on a 64-bit windows 10 computer with 8GB RAM. To evaluate the model, several test problems with different number of flights, aircrafts and planning days were used. The information used was obtained from the Emirates flies corporation.

\subsection{Emirates Flies}

Dubai is a famous city for luxury shopping, modern architect and lively scenes. Different flights bring many tourists and shoppers to this city. In 2015, Dubai attracted 14.2 million visitors (https://www.statista.com). Emirate flies is one of the biggest companies in this city. Weakly, over 1500 flights leave Dubai to more than 80 countries with more than 230 aircrafts (https://www.emirates.com). Our model was investigated based on the flight information from this corporation. Table 4 presents the levels and ranges of the parameters used in the model. 
Table 4. Summary of data

\begin{tabular}{|c|c|c|}
\hline Factors & Parameter & Basis \\
\hline Flight information & $F$ & \multirow{2}{*}{ https://www.emirates.com } \\
\hline Aircraft information & $T$ & \\
\hline Aircraft properties & $c_{1}^{i . t}, c_{2}^{i . t}, c_{3}^{i . t}, c_{4}^{i . t}$ & [13] \\
\hline Aircraft capacity & $C a p_{t}$ & \multirow{2}{*}{$\begin{array}{l}\text { https://www.boeing.com } \\
\text { https://www.airbus.com }\end{array}$} \\
\hline Minimum and maximum speed for aircraft & $s p_{i t}^{\min }, s p_{i t}^{\max }$ & \\
\hline Airport congestions & $e_{o n_{i}}, e_{d n_{i}}$ & \multirow{2}{*}[33]{} \\
\hline $\mathrm{CO}_{2}$ emission per kg energy consumption & $\tau$ & \\
\hline Fuel cost and $\mathrm{CO}_{2}$ emission cost by $\mathrm{kg}$ & $C_{f u e l}, C_{C o 2}$ & $\begin{array}{l}\text { International Air Transport } \\
\text { Association (IATA) }\end{array}$ \\
\hline Cruise flight time cost & $\gamma$ & {$[34]$} \\
\hline $\begin{array}{l}\text { Maximum flight time between successive } \\
\text { maintenances }\end{array}$ & $\delta_{t}^{m}$ & $\begin{array}{c}\text { Federal Aviation } \\
\text { Administrative constraints }\end{array}$ \\
\hline
\end{tabular}

\subsection{Model Evaluation}

Since there is a conflict between the two defined objectives, various measures were needed to evaluate the model. First, the model was studied alone and some metrics were used to measure its performance. Then, some scenarios were defined and the performance of the model was compared with them based on different metrics.

\subsection{Performance Measurement}

We used five measures to evaluate the model as described below.

Cardinality of Pareto frontier and non-dominated solution (CRD): This gives the number of obtained Pareto solutions.

Spacing metric (SPC): This metric shows how solutions are distributed along the Pareto frontier [37]:

$$
S P C=\frac{\left[\frac{1}{C R D_{N D S}(A)} \sum_{i=a}^{C R D}\left(d_{a}-\bar{d}\right)^{2}\right]^{1 / 2}}{\bar{d}},
$$

Where $\bar{d}=\frac{1}{C R D} \sum_{a=1}^{C R D} d_{a}$ and $d_{a}$ is the Euclidean distance between solution $a$ and its closest solution in the Pareto frontier. Smaller values of SPC means the solutions are distributed more evenly along the relevant Pareto frontier.

CPU time: This metric shows the time taken to solve a problem.

Two remaining metrics were also used to compare the model with scenarios. The scenarios include performing flights with random, minimum, maximum and average speed levels. The model 
and scenarios are shown by $U(U=1,2,3,4$ and 5, respectively representing the proposed model, random scenario, minimum scenario, maximum scenario and average scenario).

Quality metric $\left(Q M_{U}\right)$ : In this metric, all generated solutions from different $U$ are put together. Then, all non-dominated solutions are identified. The share of each $U$ from all non-dominated solutions is calculated by $Q M_{U}$ :

$$
Q M_{U}=\frac{\text { The number of non-dominated solutions from } U}{\text { obtained non-dominated solutions from all } U \text { togheter }}
$$

Where $0 \leq Q M_{1} \leq 1$ and $Q M_{1}+Q M_{2}+Q M_{3}+Q M_{4}+Q M_{5}=1$. Higher value of this metric shows the ability of $U$ to dominate more Pareto solutions generated by other $U$.

Distance from ideal and nadir points $\left(\boldsymbol{R}_{a, U}\right): R_{a, U}$ calculates the distance of solution $a$ in $U$ from ideal and nadir points. This metric is similar to $R_{a}$ in TOPSIS procedure (Algorithm 1 ). The more value of the metric means the less distance to the ideal point and the more distance to the nadir point.

\subsection{Model Performance Solved by Augmented $\varepsilon$-constraint Method}

We solved the model for 18 test problems and used CRD, SPC and CPU time to evaluate its performance. Table 5 shows the results. We considered the grid points to be equal to 10 .

Table 5. CRD, SPC and CPU time metrics for performance of the model

\begin{tabular}{ccccc}
\hline Problem & $\boldsymbol{F} \times \boldsymbol{T} \times \boldsymbol{D}$ & CRD & SPC & CPU time (in seconds) \\
\hline 1 & $10 \times 3 \times 2$ & 9 & 0.27 & 22.18 \\
2 & $10 \times 3 \times 4$ & 11 & 0.38 & 25.10 \\
3 & $10 \times 4 \times 2$ & 10 & 0.35 & 30.90 \\
4 & $10 \times 4 \times 4$ & 8 & 0.26 & 44.65 \\
5 & $10 \times 5 \times 2$ & 9 & 0.41 & 66.71 \\
6 & $10 \times 5 \times 4$ & 6 & 0.17 & 69.41 \\
7 & $15 \times 3 \times 2$ & 5 & 0.32 & 68.20 \\
8 & $15 \times 3 \times 4$ & 4 & 0.32 & 75.13 \\
9 & $15 \times 4 \times 2$ & 5 & 0.08 & 106.14 \\
10 & $15 \times 4 \times 4$ & 8 & 0.35 & 125.17 \\
11 & $15 \times 5 \times 2$ & 7 & 0.32 & 182.65 \\
12 & $15 \times 5 \times 4$ & 4 & 0.24 & 200.10 \\
13 & $20 \times 3 \times 2$ & 6 & 0.33 & 223.74 \\
14 & $20 \times 3 \times 4$ & 8 & 0.26 & 226.12 \\
15 & $20 \times 4 \times 2$ & 7 & 0.35 & 242.74 \\
16 & $20 \times 4 \times 4$ & 8 & 0.17 & 260.09 \\
17 & $20 \times 5 \times 2$ & 6 & 0.25 & 305.40 \\
18 & $20 \times 5 \times 4$ & 9 & 0.10 & 332.80 \\
\hline
\end{tabular}

In all the test problems, the model obtained the different Pareto solutions. Each Pareto solution has its own schedule, aircraft assignment and maintenance routing. More Pareto solutions provide more choices. It gives the managers more flexibility to survey more alternatives. Besides the number of Pareto solutions, their distribution is also important. If solutions are concentrated in a 
finite feasible space, then there will be no big difference between them. In this case, the values of the objectives are not significantly different. It is ideal to have the solutions distributed more evenly in the Pareto frontier. In this case, the managers can examine various alternatives with different results. It allows them to consider various criteria to select the ideal solution. All the test problems were solved to achieve evenly distributed solutions in reasonable times. Size of the problem according to the numbers of flights, aircrafts and planning days affects the CPU times.

\subsection{Comparing Model with Scenarios}

Four scenarios were defined. The flights were performed with random, minimum, maximum and average speed in these scenarios. All test problems were collected from the Emirates flies. We used all scenarios in the test problems. In other words, the flights of published schedule from Emirates flies (in all test problems), as performed in practice, were adopted with random, minimum, maximum and average speed levels. TEC and PSL were calculated for these scenarios. We compared the generated solutions by scenarios with the obtained solutions by the model (shown in the previous section). We adopted the scenarios with published schedule in Table 2 and the generated solutions by the scenarios were compared with the ones obtained by the model. Fig. 4 shows the comparison results.

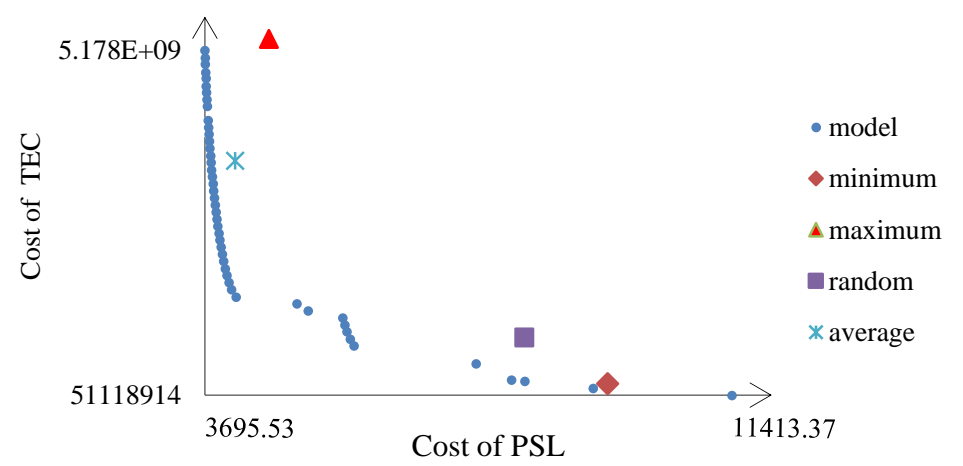

Figure 4. Non-dominated solutions for scenarios and the model

The model generated different Pareto solutions while each scenario achieved one solution. The model generated high quality solutions which dominated all the solutions obtained by scenarios. It means that $Q M_{1}=1$ and $Q M_{2}=Q M_{3}=Q M_{4}=Q M_{5}=0$. Distances from the ideal and nadir points were calculated for all the solutions. Each solution has its own distance from the ideal point. We calculated the average distance for the Pareto solutions obtained by the model and compared it with distance of solutions generated by the scenarios. The average distance was calculated as follows:

$$
\bar{R}_{a, U}=\frac{\sum_{a=1}^{C R D} R_{a, U}}{C R D}, \quad U=1
$$

The results show the shortest distance being due to the model. The average distance metric for the model is 0.82 , while this metric for scenarios $U=2,3,4$ and 5 are $0.68,0.58,0.40$ and 0.52 , respectively. The more the distance metric is closer to 1 , the shorter distance the solution has from the ideal solution and the longer distance it has from the negative ideal solution. The spacing metric for the model is 0.27 which shows the solutions of the model were distributed evenly. The same 
comparison was done between the scenarios and 18 test problems. Table 6 shows the results. Note that, we calculated the average distance of the Pareto solutions obtained by the model.

Table 6. Comparing the model and scenarios based on $\mathrm{QM}_{\mathrm{U}}$ and $\mathrm{R}_{\mathrm{a}, U}$

\begin{tabular}{|c|c|c|c|c|c|c|c|c|c|c|c|}
\hline \multirow{2}{*}{ Prob. } & \multirow{2}{*}{$F \times T \times D$} & \multicolumn{5}{|c|}{$Q M_{U}$} & \multirow{2}{*}{$\begin{array}{c}\bar{R}_{a, U} \\
\boldsymbol{u}=\mathbf{1}\end{array}$} & \multicolumn{4}{|c|}{$R_{a, U}$} \\
\hline & & $u=1$ & $u=2$ & $u=3$ & $u=4$ & $u=5$ & & $u=2$ & $u=3$ & $u=4$ & $u=5$ \\
\hline 1 & $10 \times 3 \times 2$ & 1 & 0 & 0 & 0 & 0 & 0.78 & 0.62 & 0.57 & 0.40 & 0.60 \\
\hline 2 & $10 \times 3 \times 4$ & 1 & 0 & 0 & 0 & 0 & 0.81 & 0.68 & 0.62 & 0.32 & 0.54 \\
\hline 3 & $10 \times 4 \times 2$ & 1 & 0 & 0 & 0 & 0 & 0.84 & 0.62 & 0.52 & 0.29 & 0.34 \\
\hline 4 & $10 \times 4 \times 4$ & 1 & 0 & 0 & 0 & 0 & 0.80 & 0.52 & 0.43 & 0.34 & 0.39 \\
\hline 5 & $10 \times 5 \times 2$ & 0.89 & 0 & 0.11 & 0 & 0 & 0.80 & 0.65 & 0.51 & 0.45 & 0.40 \\
\hline 6 & $10 \times 5 \times 4$ & 1 & 0 & 0 & 0 & 0 & 0.84 & 0.72 & 0.65 & 0.41 & 0.52 \\
\hline 7 & $15 \times 3 \times 2$ & 1 & 0 & 0 & 0 & 0 & 0.78 & 0.54 & 0.57 & 0.37 & 0.42 \\
\hline 8 & $15 \times 3 \times 4$ & 1 & 0 & 0 & 0 & 0 & 0.84 & 0.57 & 0.63 & 0.52 & 0.50 \\
\hline 9 & $15 \times 4 \times 2$ & 1 & 0 & 0 & 0 & 0 & 0.86 & 0.62 & 0.54 & 0.38 & 0.48 \\
\hline 10 & $15 \times 4 \times 4$ & 0.88 & 0 & 0.12 & 0 & 0 & 0.81 & 0.68 & 0.43 & 0.38 & 0.42 \\
\hline 11 & $15 \times 5 \times 2$ & 1 & 0 & 0 & 0 & 0 & 0.77 & 0.61 & 0.53 & 0.29 & 0.48 \\
\hline 12 & $15 \times 5 \times 4$ & 1 & 0 & 0 & 0 & 0 & 0.83 & 0.54 & 0.44 & 0.49 & 0.50 \\
\hline 13 & $20 \times 3 \times 2$ & 1 & 0 & 0 & 0 & 0 & 0.74 & 0.59 & 0.48 & 0.50 & 0.43 \\
\hline 14 & $20 \times 3 \times 4$ & 1 & 0 & 0 & 0 & 0 & 0.90 & 0.72 & 0.72 & 0.68 & 0.70 \\
\hline 15 & $20 \times 4 \times 2$ & 0.85 & 0 & 0.15 & 0 & 0 & 0.87 & 0.82 & 0.71 & 0.64 & 0.70 \\
\hline 16 & $20 \times 4 \times 4$ & 1 & 0 & 0 & 0 & 0 & 0.93 & 0.85 & 0.74 & 0.70 & 0.77 \\
\hline 17 & $20 \times 5 \times 2$ & 1 & 0 & 0 & 0 & 0 & 0.93 & 0.63 & 0.52 & 0.60 & 0.62 \\
\hline 18 & $20 \times 5 \times 4$ & 0.84 & 0 & 0.16 & 0 & 0 & 0.84 & 0.72 & 0.58 & 0.54 & 0.54 \\
\hline \multicolumn{2}{|c|}{ Average } & 0.97 & 0 & 0.03 & 0 & 0 & $\mathbf{0 . 8 3}$ & 0.65 & 0.57 & 0.46 & 0.51 \\
\hline
\end{tabular}

According to $Q M_{U}$, the proposed model could mostly dominate the generated solutions by other scenarios. None of the obtained solutions by the scenarios could dominate the model. $R_{a, U}$ shows that the obtained solutions by the model were closer to the ideal solution as compared to the ones corresponding to the scenarios. The model produced better results. This means that the model with $\mathrm{CSC}$ can reduce the fuel consumption and improve the service level (reduce the cost of the service level). In this way, emission of $\mathrm{CO}_{2}$ is also reduced. We calculated the average cost on TEC and PSL for the obtained solutions by the model and compared them with the costs generated by the scenarios. The amount of improvement in cost was calculated according to equations (58) and (59). $T E C_{\text {scenario }(U)}$ and $T E C_{\text {model }}$ represent the TEC cost for the scenario $U$ and the average cost on TEC for the obtained solutions by the model, respectively. Also, $P S L_{\text {scenario }(U)}$ and $P S L_{\text {model }}$ represent the PSL cost for the scenario $U$ and the average cost on PSL for obtained solutions by the model, respectively:

$$
\begin{aligned}
& \text { Average improvement in TEC cost }=\frac{T E C_{\text {scenario }(U)}-T E C_{\bmod e l}}{T E C_{\text {scenario }(U)}}, \\
& \text { Average improvement in PSL cost }=\frac{P S L_{\text {scenario }(U)}-P S L_{\text {mod } e l}}{P S L_{\text {scenario }(U)}} .
\end{aligned}
$$

Tables 7 and 8 show the results of improvements in TEC and PSL costs. 
Table 7. Improvement in TEC cost incurred by the model as compared to scenario $U$

\begin{tabular}{cccccc}
\hline Prob. & $\boldsymbol{F} \times \boldsymbol{T} \times \boldsymbol{D}$ & $\boldsymbol{U}=\mathbf{2}$ & $\boldsymbol{U}=\mathbf{3}$ & $\boldsymbol{U}=\mathbf{4}$ & $\boldsymbol{U}=\mathbf{5}$ \\
\hline 1 & $10 \times 3 \times 2$ & 0.24 & 0.05 & 0.60 & 0.22 \\
2 & $10 \times 3 \times 4$ & 0.34 & 0.00 & 0.38 & 0.18 \\
3 & $10 \times 4 \times 2$ & 0.25 & 0.04 & 0.45 & 0.13 \\
4 & $10 \times 4 \times 4$ & 0.27 & 0.11 & 0.58 & 0.23 \\
5 & $10 \times 5 \times 2$ & 0.21 & 0.05 & 0.41 & 0.18 \\
6 & $10 \times 5 \times 4$ & 0.30 & 0.08 & 0.39 & 0.18 \\
7 & $15 \times 3 \times 2$ & 0.52 & 0.09 & 0.63 & 0.22 \\
8 & $15 \times 3 \times 4$ & 0.25 & 0.00 & 0.52 & 0.37 \\
9 & $15 \times 4 \times 2$ & 0.32 & 0.07 & 0.58 & 0.24 \\
10 & $15 \times 4 \times 4$ & 0.28 & 0.04 & 0.37 & 0.18 \\
11 & $15 \times 5 \times 2$ & 0.37 & 0.02 & 0.49 & 0.33 \\
12 & $15 \times 5 \times 4$ & 0.24 & 0.10 & 0.54 & 0.32 \\
13 & $20 \times 3 \times 2$ & 0.38 & 0.08 & 0.38 & 0.24 \\
14 & $20 \times 3 \times 4$ & 0.27 & 0.04 & 0.41 & 0.15 \\
15 & $20 \times 4 \times 2$ & 0.32 & 0.04 & 0.39 & 0.25 \\
16 & $20 \times 4 \times 4$ & 0.43 & 0.09 & 0.41 & 0.15 \\
17 & $20 \times 5 \times 2$ & 0.30 & 0.02 & 0.38 & 0.15 \\
18 & $20 \times 5 \times 4$ & 0.21 & 0.03 & 0.46 & 0.22 \\
\hline \multicolumn{2}{c}{ Average } & $\mathbf{0 . 3 0}$ & $\mathbf{0 . 0 5}$ & $\mathbf{0 . 4 6}$ & $\mathbf{0 . 2 1}$ \\
\hline
\end{tabular}

Table 8. Improvement in PSL cost incurred by the model as compared to scenario $U$

\begin{tabular}{cccccc}
\hline Prob. & $\mathbf{F} \times \mathbf{T} \times \mathbf{D}$ & $\mathbf{U = 2}$ & $\mathbf{U = 3}$ & $\mathbf{U = 4}$ & $\mathbf{U = 5}$ \\
\hline 1 & $10 \times 3 \times 2$ & 0.25 & 0.40 & 0.03 & 0.06 \\
2 & $10 \times 3 \times 4$ & 0.27 & 0.36 & 0.05 & 0.10 \\
3 & $10 \times 4 \times 2$ & 0.16 & 0.27 & 0.03 & 0.28 \\
4 & $10 \times 4 \times 4$ & 0.37 & 0.45 & 0.00 & 0.07 \\
5 & $10 \times 5 \times 2$ & 0.23 & 0.57 & 0.07 & 0.10 \\
6 & $10 \times 5 \times 4$ & 0.48 & 0.77 & 0.10 & 0.15 \\
7 & $15 \times 3 \times 2$ & 0.40 & 0.48 & 0.00 & 0.09 \\
8 & $15 \times 3 \times 4$ & 0.14 & 0.33 & 0.04 & 0.16 \\
9 & $15 \times 4 \times 2$ & 0.31 & 0.30 & 0.02 & 0.11 \\
10 & $15 \times 4 \times 4$ & 0.10 & 0.14 & 0.00 & 0.11 \\
11 & $15 \times 5 \times 2$ & 0.20 & 0.38 & 0.10 & 0.16 \\
12 & $15 \times 5 \times 4$ & 0.25 & 0.28 & 0.05 & 0.12 \\
13 & $20 \times 3 \times 2$ & 0.37 & 0.42 & 0.09 & 0.23 \\
14 & $20 \times 3 \times 4$ & 0.20 & 0.24 & 0.00 & 0.13 \\
15 & $20 \times 4 \times 2$ & 0.23 & 0.42 & 0.05 & 0.21 \\
16 & $20 \times 4 \times 4$ & 0.25 & 0.32 & 0.09 & 0.16 \\
17 & $20 \times 5 \times 2$ & 0.32 & 0.38 & 0.05 & 0.10 \\
18 & $20 \times 5 \times 4$ & 0.16 & 0.26 & 0.02 & 0.06 \\
\hline \multicolumn{2}{c}{ Average } & $\mathbf{0 . 2 6}$ & $\mathbf{0 . 3 8}$ & $\mathbf{0 . 0 4}$ & $\mathbf{0 . 1 3}$ \\
\hline
\end{tabular}

In scenario 3, flights were performed with minimum speed level. TEC and its cost were minimized at this level. In Table 7, the proposed model could improve TEC cost as compared to scenario 3. This is due to the more use of highly-efficient aircrafts. Also, the model achieved a significant improvement in TEC cost as compared to other scenarios. The model has a good performance in fuel consumption and $\mathrm{CO}_{2}$ emission. Reduction of TEC cost leads to a lower damaging effect on the environment. Besides these advantages, the model also improved upon PSL. 
In scenario 4, flights were performed at maximum speed level, and PSL was maximized (cost was minimized) at this level. The proposed model could improve upon PSL as compared to scenario 4. This is due to the proper scheduling for flights. Figs. 5 and 6 show the value of PSL and TEC.

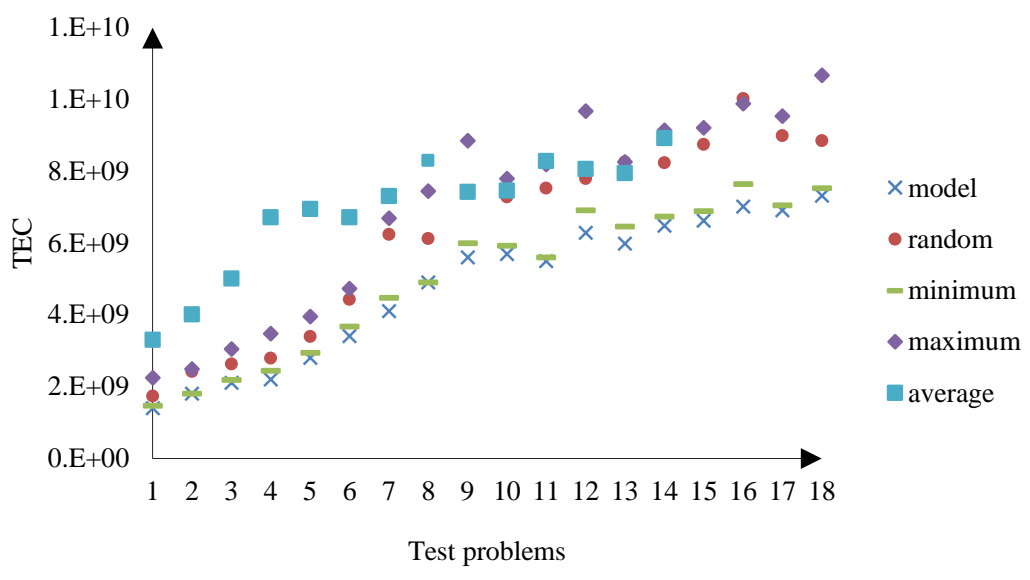

Figure 5. Value of TEC in test problems

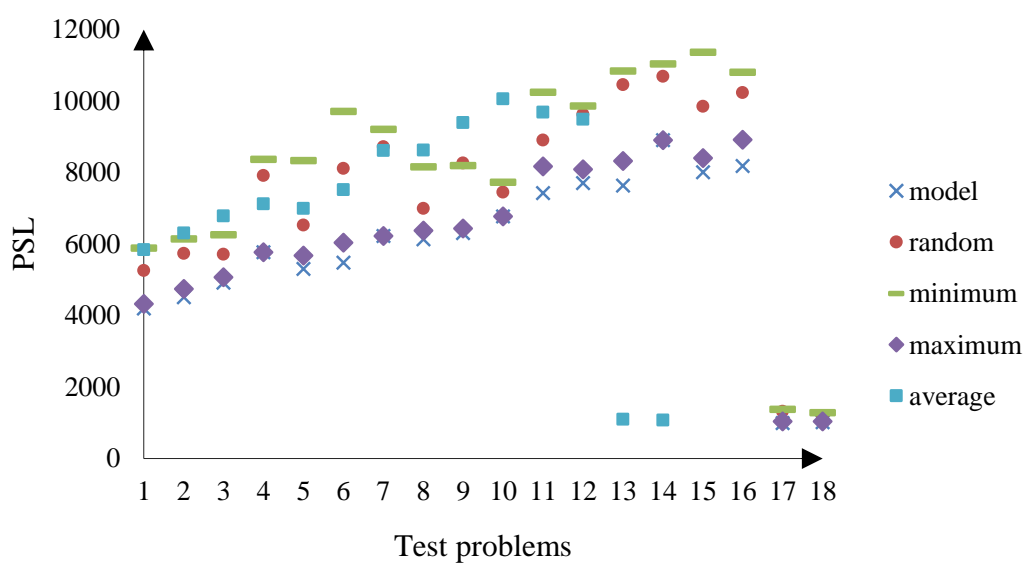

Figure 6. Value of PSL in test problems

\section{Conclusion}

We investigated an integration of the schedule design, aircraft assignment and maintenance routing. On one side the environmental issues and on the other side obtainment of competitive advantages to attract passengers were the motivation to propose a bi-objective mixed-integer nonlinear programming model. The above issues were considered as two conflicting objectives. Cruise speed control made it possible to attend to the conflict. We proposed a new approach to model multiday planning. Also, we used the augmented $\varepsilon$-constraint method to solve the model. We used different test problems based on real data obtained from the Emirates flies to evaluate the model. The results showed the model could obtain high-quality solutions in reasonable times. Also, various scenarios were defined to compare the effectiveness of the model. It was observed that the model improved upon the TEC and PSL as compared to the scenarios. To extend our work here, 
integration of gate planning with the proposed model is proposing. Also, efficient heuristic and metaheuristic algorithms may be developed to solve large problems.

\section{References}

[1] Abdullah, M.A., Chew, B.C.,and Hamid, S.R. (2016), Benchmarking Key Success Factors for the Future Green Airline Industry, Procedia-Social and Behavioral Sciences, 224, 246-253.

[2] Airportwatch. (2014), IPCC report says transport contributes $27 \%$ of global $\mathrm{CO}_{2}$ and could double by 2050 under BAU. < http://www.airportwatch.org.uk>

[3] Aktürk, M.S., Atamtürk, A., and Gürel, S. (2014), Aircraft rescheduling with cruise speed control, Operations Research, 62(4), 829-845.

[4] Barnhart, C., Belobaba, P., and Odoni, A.R. (2003), Applications of operations research in the air transport industry, Transportation science, 37(4), 368-391.

[5] Barnhart, C., and Cohn, A. (2004), Airline schedule planning: Accomplishments and opportunities, Manufacturing \& service operations management, 6(1), 3-22.

[6] Boeing, Jet prices. (2016), http://www.boeing.com/company/aboutbca/index.page\%23/prices, visit November 2016.

[7] Cheikh, M., Jarboui, B., Loukil, T., and Siarry, P. (2010), A method for selecting Pareto optimal solutions in multiobjective optimization, Journal of Informatics and Mathematical Sciences, 2(1), 51-62.

[8] Chow, C.K.W. (2015), On-time performance, passenger expectations and satisfaction in the Chinese airline industry, Journal of Air Transport Management, 47, 39-47.

[9] Clausen, J., Larsen, A., Larsen, J., and Rezanova, N.J. (2010), Disruption management in the airline industry: concepts, models and methods, Computers \& Operations Research, 37(5), 809-821.

[10] Cui, Q., Li, Y., Yu, C.L., and Wei, Y.M. (2016), Evaluating energy efficiency for airlines: an application of Virtual Frontier Dynamic Slacks Based Measure, Energy, 113, 1231-1240.

[11] Dalmau, R., and Prats, X. (2015), Fuel and time savings by flying continuous cruise climbs: Estimating the benefit pools for maximum range operations, Transportation Research Part D: Transport and Environment, 35, 62-71.

[12] Duran, A.S., Gürel, S., and Aktürk, M.S. (2015), Robust airline scheduling with controllable cruise times and chance constraints, IIE Transactions, 47(1), 64-83.

[13] EUROCONTROL. (2012), User manual for the base of aircraft data (BADA) Revision 3.10. Technical report, EEC Technical/Scientific Report 12/04/10-45, Eurocontrol, Eurocontrol Experimental Centre, Bretigny-sur-Orge, France

[14] Franco, A., and Rivas, D. (2014), Analysis of optimal aircraft cruise with fixed arrival time including wind effects, Aerospace Science and Technology, 32(1), 212-222.

[15] Fukui, H., and Miyaoshi, C. (2017), The impact of aviation fuel tax on fuel consumption and carbon emissions: The case of the US airline industry, Transportation Research Part D: Transport and Environment, 50, 234-253.

[16] Glover, F., and Woolsey, E. (1974), Converting the 0-1 polynomial programming problem to a 0-1 linear program, Operations research, 22(1), 180-182.

[17] Gronau, R. (1970), The effect of traveling time on the demand for passenger transportation, Journal of Political Economy, 78(2), 377-394.

[18] Gürkan, H., Gürel, S., and Aktürk, M.S. (2016), An integrated approach for airline scheduling, aircraft fleeting and routing with cruise speed control, Transportation Research Part C: Emerging Technologies, 68, 38-57. 
[19] Hagmann, C., Semeijn, J., and Vellenga, D.B. (2015), Exploring the green image of airlines: Passenger perceptions and airline choice, Journal of Air Transport Management, 43, 37-45.

[20] Hapsari, R., Clemes, M., and Dean, D. (2016), The Mediating Role of Perceived Value on the Relationship between Service Quality and Customer Satisfaction: Evidence from Indonesian Airline Passengers, Procedia Economics and Finance, 35, 388-395.

[21] Holbrook, M.B. (1994), The nature of customer value: an axiology of services in the consumption experience, Service quality: New directions in theory and practice, 21, 2171.

[22] Hu, Y., Song, Y., Zhao, K., and Xu, B. (2016), Integrated recovery of aircraft and passengers after airline operation disruption based on a GRASP algorithm, Transportation research part E: logistics and transportation review, 87, 97-112.

[23] Hussain, R., Al Nasser, A., and Hussain, Y.K. (2015), Service quality and customer satisfaction of a UAE-based airline: An empirical investigation, Journal of Air Transport Management, 42, 167-175.

[24] Hwang, C.L., and Yoon, K. (1981), Multiple Attribute Decision Making: Methods and Applications, New York: Springer-Verlag.

[25] Jiang, H., and Zhang, Y. (2016), An investigation of service quality, customer satisfaction and loyalty in China's airline market, Journal of Air Transport Management, 57, 80-88.

[26] Kurtulmuşoğlu, F.B., Can, G.F., and Tolon, M. (2016), A voice in the skies: Listening to airline passenger preferences, Journal of Air Transport Management, 57, 130-137.

[27] Lee, J.J. (2010), Can we accelerate the improvement of energy efficiency in aircraft systems, Energy conversion and management, 51(1), 189-196.

[28] Lim, S.H., and Hong, Y. (2014), Fuel hedging and airline operating costs, Journal of Air Transport Management, 36, 33-40.

[29] Malakooti, B., and Raman, V. (2000), Clustering and selection of multiple criteria alternatives using unsupervised and supervised neural networks, Journal of Intelligent Manufacturing, 11(5), 435-451.

[30] Mavrotas, G. (2009), Effective implementation of the $\varepsilon$-constraint method in multiobjective mathematical programming problems, Applied mathematics and computation, 213(2), 455-465.

[31] Norouzi, N., Tavakkoli-Moghaddam, R., Ghazanfari, M., Alinaghian, M., and Salamatbakhsh, A. (2012), A new multi-objective competitive open vehicle routing problem solved by particle swarm optimization, Networks and Spatial Economics, 12(4), 609-633.

[32] Parmentier, A. (2013), Aircraft Routing: Complexity and Algorithms, Master's thesis, Ecole des Ponts ParisTech.

[33] Şafak, Ö., Gürel, S., and Aktürk, M.S. (2017), Integrated aircraft-path assignment and robust schedule design with cruise speed control, Computers \& Operations Research, $84,127-145$.

[34] Skorupski, J. (2015), The risk of an air accident as a result of a serious incident of the hybrid type, Reliability Engineering \& System Safety, 140, 37-52.

[35] Taboada, H.A., Baheranwala, F., Coit, D.W., and Wattanapongsakorn, N. (2007), Practical solutions for multi-objective optimization: An application to system reliability design problems, Reliability Engineering \& System Safety, 92(3), 314-322.

[36] Talluri, K.T. (1998), The four-day aircraft maintenance routing problem, Transportation Science, 32(1), 43-53.

[37] Tan, K. C., Goh, C. K., Yang, Y. J., and Lee, T. H. (2006), Evolving better population distribution and exploration in evolutionary multi-objective optimization, European 
Journal of Operational Research, 171(2), 463-495.

[38] Turgut, E.T., Cavcar, M., Usanmaz, O., Canarslanlar, A.O., Dogeroglu, T., Armutlu, K., and Yay, O.D. (2014), Fuel flow analysis for the cruise phase of commercial aircraft on domestic routes, Aerospace Science and Technology, 37, 1-9.

[39] Y1lmaz, İ. (2017), Emissions from passenger aircrafts at Kayseri Airport, Turkey, Journal of Air Transport Management, 58, 176-182. 